\title{
Thermal properties of pressure sintered alumina-graphene composites
}

\author{
Paweł Rutkowski $^{1}$ Piotr Klimczyk ${ }^{2}$ - Lucyna Jaworska ${ }^{2}$ Ludosław Stobierski ${ }^{1}$. \\ Aleksandra Dubiel ${ }^{1}$
}

Received: 18 January 2015/Accepted: 2 April 2015/Published online: 1 May 2015

(c) The Author(s) 2015. This article is published with open access at Springerlink.com

\begin{abstract}
The work concerns the alumina-graphene materials sintered by two different pressure methods. The different particle sizes of graphene were used. The preparation route of the matrix-graphene mixture was discussed in the paper. The so-prepared compositions with different amount of graphene were hot-pressed and spark plasma sintered. The influence on uniaxial pressure during the sintering process on the microstructure was presented by the SEM microstructural observations and ultrasonic measurements. The material with unidirectional oriented graphene particles was prepared, and the anisotropy was even higher than $30 \%$ for 10 mass $\%$ of graphene additive. The influence of graphene orientation as an effect of pressing process on the thermal properties was analysed. The anisotropy of thermal conductivity was $90 \%$ for 10 mass $\%$ of graphene. The thermal diffusivity and thermal conductivity of composites manufactured by hotpressing and spark plasma sintering method were compared. The experiment-based calculation of the specific heat versus temperature was presented in the paper. The thermal expansion coefficient was determined by dilatometric method. The thermal stability was analysed by thermogravimetric method, and it showed that composites with up to 2 mass $\%$ of graphene can work at temperatures higher than $700{ }^{\circ} \mathrm{C}$.
\end{abstract}

Paweł Rutkowski

pawelr@agh.edu.pl; Pawel.Rutkowski@agh.edu.pl

1 Faculty of Material Science and Ceramics, AGH University of Science and Technology, al. Mickiewicza 30, 30-059 Kraków, Poland

2 Institute of Advanced Manufacturing Technology, ul. Wroclawska 37A, 30-011 Kraków, Poland
Keywords Alumina - Graphene - Microstructure · Thermal stability $\cdot$ Thermal conductivity

\section{Introduction}

In case of ceramic materials, the graphene particles are used to improve the mechanical properties of such wellknown material as alumina, silicon nitride and silicon carbide [1-20]. As a two-dimensional phase, graphene shows very good electrical and thermal properties [21, 22]. That is, why this phase is very often deposited on the ceramic or other kinds of surfaces. The electrical properties of this phase, in case of ceramic material, can help at shaping polycrystalline sintered materials by use of electroerosion methods. For ceramics, as a materials working, at high-temperature conditions, the addition of graphene flake gives a hope of thermal properties improvement. The typical methods of ceramic-graphene manufacturing are hot-pressing (HP) and spark plasma sintering (SPS) $[9,12,18,24]$. The uniaxial pressing, which helps to densify the materials during the sintering, becomes a problem for ceramic-2D phase materials. The one direction of applied pressure causes the orientation of two-dimensional phase in the ceramic matrix [23,24]. This situation can lead to the anisotropy of heat transport of ceramic matrix composites. In the case of hexagonal boron nitride dispersed phase, the thermal properties (conductivity) decrease in all of directions in comparison with reference pure material [23]. It is caused mostly by agglomeration of hexagonal boron nitride particles, where the agglomerates are porous. Different situation is in case of graphene, where even well-packed groups of oriented flakes lead to an improvement of thermal conductivity in direction perpendicular to pressing axis so in the direction of oriented graphene particles' planes. It has 
place in silicon nitride-graphene composites [24], where introduce oriented graphene phase leads additionally to large difference in thermal conductivity in different directions of sintered bodies.

In this work, the experiments are focused on thermal behaviour of alumina matrix composites with disperses different size graphene particle. The thermal properties in this work are discussed not only in the field of graphene orientation in ceramic body but also in the field of manufacturing process conditions. For that purpose, the two-phase polycrystalline materials were obtained by HP and SPS methods. On the sintered under uniaxial pressure materials, the thermal diffusivity and thermal conductivity were measured and compered with manufacturing method and anisotropy of the composites.

The one very important and negative property of graphene is lack of the resistance to reaction with oxygen. That is why the produced composite materials were thermogravimetry tested to show/determine maximal working temperature in air conditions in function of graphene concentration.

The aim of the work was to investigate the influence of technological conditions and graphene content on thermal properties of alumina-graphene composites. The additional parameter taken under discussion was the correlation between material anisotropy and thermal conductivity.

\section{Preparation}

$\mathrm{Al}_{2} \mathrm{O}_{3}$-graphene composites were prepared using commercial powders listed in Table 1. The graphene addition to the aluminium oxide matrix was established as follows: from 0 to 10 mass\%.

\section{Hot-pressed composites preparation}

In the case of HP method, two kinds of mixtures were prepared: alumina with $0-10$ mass $\%$ of $8 \mathrm{~nm}$ graphene and alumina with $0-2$ mass $\%$ of $4 \mathrm{~nm}$ graphene. The powder mixtures were homogenized for $10 \mathrm{~h}$ in propanol using a rotary-vibratory mill and alumina grinding media. Dried and granulated powders were hot-pressed (Thermal Technology LLC) at $1400{ }^{\circ} \mathrm{C}$ for $1 \mathrm{~h}$ under $25 \mathrm{MPa}$ in argon flow. The heating rate was $10{ }^{\circ} \mathrm{C} \mathrm{min}^{-1}$. Sintered bodies with a diameter of $50 \mathrm{~mm}$ were obtained.

\section{Spark plasma sintered composites preparation}

In the case of SPS method, the alumina powder (A16SG, Almatis) with addition of 0.3 mass $\%$ of $\mathrm{MgO}$ nanopowder (Inframat) has been used as a starting material. Multilayer graphene nanoparticles-GNP, characterized in Table 1, were used as fillers for alumina ceramic matrix composites.

The mixtures, containing alumina with addition of GPLs, grades $\mathrm{Gn}(12), \mathrm{Gn}(8)$ and $\mathrm{Gn}(4)$, respectively, were prepared using Fritsch Pulverisette 6 planetary mill equipped with $\mathrm{ZrO}_{2}$ grinding vessel and balls. Powders were milled in isopropanol with rotation speed of $200 \mathrm{rpm}$ for $8 \mathrm{~h}$. The mixtures were dried and sieved through $0.5 \mathrm{~mm}$ mesh.

The composites were sintered using SPS (FCT system, Germany) in the temperature $1550{ }^{\circ} \mathrm{C}$ for $10 \mathrm{~min}$ and

Table 1 Materials characterization for composite preparation

\begin{tabular}{|c|c|c|}
\hline Powder ID & Supplier & Characteristics \\
\hline $\begin{array}{l}\text { Submicron alumina } \\
\text { Taimicron TM-DAR }\end{array}$ & Taimei CHEMICALS CO., LTD & Average particle size $0.1 \mu \mathrm{m}$ \\
\hline $\begin{array}{l}\text { Submicron alumina } \\
\text { grade A16SG }\end{array}$ & Almatis, Germany & $0.3-0.6 \mu \mathrm{m}$ \\
\hline Graphene Gn(12) & Graphene Laboratories, Inc., USA & $\begin{array}{l}\text { Colour black, purity } 99.2 \% \\
\text { Average flake thickness } 12 \mathrm{~nm}(30-50 \text { monolayers) } \\
\text { Average particle (lateral) size: } \sim 4.5 \mu \mathrm{m}(1.5-10) \\
\text { Specific surface area } 80 \mathrm{~m}^{2} \mathrm{~g}^{-1}\end{array}$ \\
\hline Graphene Gn(8) & & $\begin{array}{l}\text { Colour black, purity } 99.9 \% \\
\text { Average flake thickness } 8 \mathrm{~nm}(20-30 \text { monolayers) } \\
\text { Average particle (lateral) size } \sim 0.5 \mu \mathrm{m}(0.15-3.0) \\
\text { Specific surface area } 100 \mathrm{~m}^{2} \mathrm{~g}^{-1}\end{array}$ \\
\hline Graphene Gn(4) & Cheap Tubes, USA & $\begin{array}{l}\text { Colour black, purity } 99 \% \\
\text { Average flake thickness }<4 \mathrm{~nm} \\
\text { Average particle (lateral) size } 1-2 \mu \mathrm{m} \\
\text { Specific surface area }>700 \mathrm{~m}^{2} \mathrm{~g}^{-1}\end{array}$ \\
\hline
\end{tabular}


applying $35 \mathrm{MPa}$ of uniaxial pressure during the whole cycle. Sintered specimens were disk-shaped with dimensions of $20 \mathrm{~mm}$ in diameter and $\sim 5 \mathrm{~mm}$ in thickness.

\section{Examination route}

Apparent density of the sintered samples was calculated basis on the Archimedes method. The phase composition of the sinters was checked by XRD diffraction (production of Philips with X-Pert HighScore software) and the Rietveld refinement determining the phase content quantitatively. Raman spectroscopy (Horriba Yvon Jobin LabRAM HR) was used for graphene phase identification. The morphology of samples was observed using the SEM technique-FEI Nova Nano SEM.

The anisotropy of elastic wave velocity was measured by ultrasonic method using UZP-1 (INCO-VERITAS) apparatus.

The thermal stability was measured in air flow by means of thermogravimetric TG measurements using STA 449 F3 Jupiter $^{\circledR}$. The measurement was taken up to temperature of $1000{ }^{\circ} \mathrm{C}$.

Heat measurements were taken on a Netzsch LFA 427 apparatus. To determine the specific heat by comparative method, Pyroceram 9606 reference material, with the known coefficient of thermal expansion and specific heat, was used. Thermal diffusivity was determined using the laser pulse method (LFA) for the reference and test material at temperatures ranging from 25 to $900{ }^{\circ} \mathrm{C}$ in argon flow. The sintered bodies were measured in pressing direction (the direction of applied pressure during manufacturing process) using the "Cape-Lehmann + pulse correction" computational model and in perpendicular direction to the applied pressure using "Radiation + pulse correction" model. At each temperature, three measurements were taken for statistical purposes. Examination of tested materials density changes as a function of temperature in the range up to $900{ }^{\circ} \mathrm{C}$ was performed by determining the coefficient of thermal expansion using a Netzsch DIL 402C dilatometer. Based on these measurements, specific heat was determined using the following formula:

$$
\begin{aligned}
c_{\mathrm{p}}^{\text {sample }}= & \frac{T_{\infty}^{\text {ref }}}{T_{\infty}^{\text {sample }}} \cdot \frac{Q^{\text {sample }}}{Q^{\text {ref }}} \cdot \frac{V^{\text {sample }}}{V^{\text {ref }}} \cdot \frac{\rho^{\text {ref }}}{\rho^{\text {sample }}} \cdot \frac{D^{\text {ref }}}{D^{\text {sample }}} \\
& \cdot \frac{d_{\text {orifice }}^{2 \text {,sample }}}{d_{\text {orificer }}^{2, \text { ref }}} \cdot c_{\mathrm{p}}^{\text {ref }}(\mathrm{T})
\end{aligned}
$$

where $c_{\mathrm{p}}$ specific heat of the sample/reference $/ \mathrm{J} \mathrm{g}^{-1} \mathrm{~K}^{-1}, T$ temperature of the sample/reference/K, $Q$ energy absorbed by the sample/reference/J, $V$ amplitude of signal gain for the sample/reference, $\rho$ apparent density of the sample/ reference $/ \mathrm{g} \mathrm{cm}^{-3}, D$ thickness of the test material $/ \mathrm{mm}$ and $d$ diameter of the measuring aperture of the sample/reference/mm. The thermal conductivity was calculated from the following equation:

$\lambda(T)=a(T) \cdot c_{\mathrm{p}}(T) \cdot \rho(T)$

where $a(T)$ thermal diffusivity $/ \mathrm{mm}^{2} \mathrm{~s}^{-1}, c_{\mathrm{p}}(T)$ specific heat $/ \mathrm{J} \mathrm{g}^{-1} \mathrm{~K}^{-1}, \rho(T)$ density of the material $/ \mathrm{g} \mathrm{cm}^{-3}$.

\section{Results and discussion}

The calculated, on the based on hydrostatic measurement, densities values of alumina-based composites obtained by HP and SPS methods are listed in Table 2. The relative density shows that in case of HP, the materials with addition up to 4 mass\% of $\mathrm{Gn}(8)$ graphene have more than $98 \%$ of theoretical density. The further increase in graphene content leads to a decrease in material densification, which reaches $95 \%$ for 10 mass $\%$ of graphene. The results obtained for SPSed composites confirm that low addition of graphene phase, independently from type of graphene, allow obtaining relative densities above $98 \%$.

The XRD measurements, made on alumina-graphene materials, allowed to detect the graphite phase in case of its higher content. The carried Raman analysis confirmed the existence of graphene in all of the manufactured sintered bodies. The Raman analyses, shown on the example HP materials, are presented in Fig. 1. The Raman spectra of graphene in manufactured composites are compatible with

Table 2 Densification of hot-pressed and spark plasma sintered alumina-graphene composites

\begin{tabular}{lllc}
\hline $\begin{array}{l}\text { Graphene } \\
\text { addition }\end{array}$ & $\begin{array}{l}\text { Pressing } \\
\text { method }\end{array}$ & $\begin{array}{l}\text { Apparent } \\
\text { density/g cm }\end{array}$ & $\begin{array}{l}\text { Relative } \\
\text { density/\% }\end{array}$ \\
\hline 0 mass\% Gn(8) & HP & 3.98 & 100 \\
0.5 mass\% Gn(8) & HP & 3.95 & 99.6 \\
1 mass\% Gn(8) & HP & 3.93 & 99.5 \\
2 mass\% Gn(8) & HP & 3.89 & 99.2 \\
4 mass\% Gn(8) & HP & 3.79 & 98.1 \\
6 mass\% Gn(8) & HP & 3.69 & 96.9 \\
8 mass\% Gn(8) & HP & 3.62 & 96.5 \\
10 mass\% Gn(8) & HP & 3.52 & 95.2 \\
0 mass\% Gn(4) & SPS & 3.90 & 98.0 \\
0.5 mass\% Gn(4) & SPS & 3.91 & 98.5 \\
1 mass\% Gn(4) & SPS & 3.90 & 98.7 \\
2 mass\% Gn(4) & SPS & 3.83 & 97.7 \\
10 mass\% Gn(4) & SPS & 3.62 & 97.8 \\
2 mass\% Gn(8) & SPS & 3.79 & 96.7 \\
2 mass\% Gn(12) & SPS & 3.90 & 99.5 \\
\hline
\end{tabular}




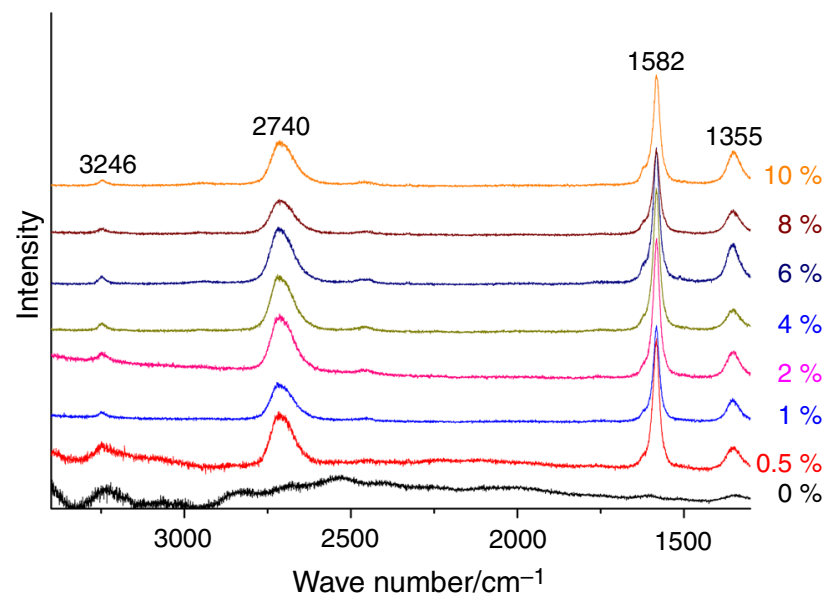

Fig. 1 Raman spectra of hot-pressed alumina-graphene composites with various addition of graphene $\mathrm{Gn}(8)$

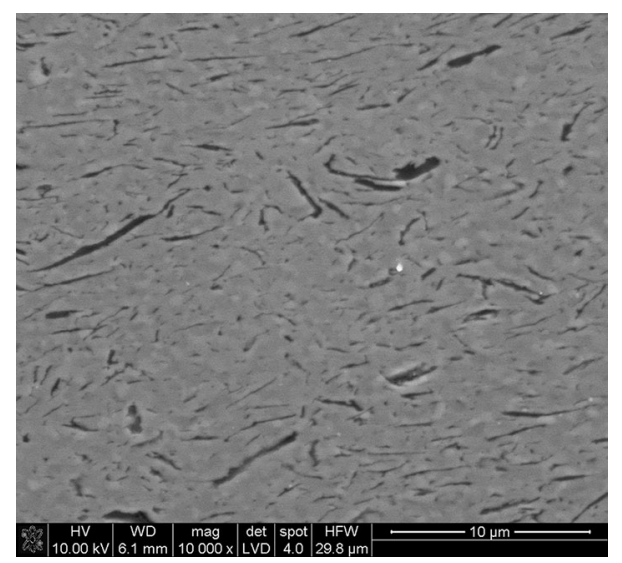

Fig. 2 SEM observations of hot-pressed composites with 4 mass $\%$ $\mathrm{Gn}(8)$ graphene content

the wavenumbers of pure graphene (powder) bands at: $3243,2717,1578$ and $1349 \mathrm{~cm}^{-1}$.

The microstructural observations were made on the polished surfaces and fractures. The examples of the results are illustrated: for hot-pressed (HP) alumina/graphene composites in Figs. 2-4 and for spark plasma sintered (SPS) in Figs. 6 and 7.

The observed microstructures in Figs. 2-4 indicate on graphene flake or group of flakes orientation perpendicularly to the applied pressure during the HP process. That situation takes place for whole range of the graphene content. To prove the orientation of the graphene particles in alumina matrix, the ultrasonic wave velocity was measured on the samples in different direction.

In the case of hot-pressed alumina matrix composites, the results of ultrasonic measurements, shown in Fig. 5, indicate on a significant increase in anisotropy of longitudinal wave velocity versus graphene content. The value exceeds even $30 \%$ for sample containing 10 mass $\%$ of

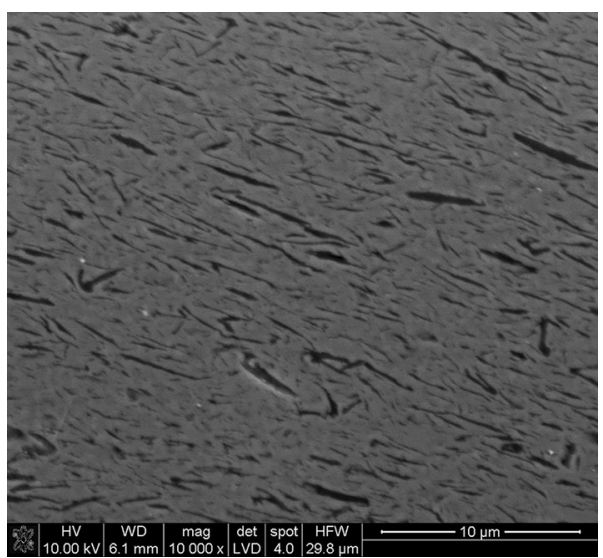

Fig. 3 SEM observations of hot-pressed composites with 8 mass\% $\mathrm{Gn}(8)$ graphene content

graphene. The results of anisotropy illustrated in Fig. 5 confirm the microstructural observation of oriented graphene flakes/groups of flakes in hot-pressed composites. The similar situation of anisotropy was recorded also in previous work of the author in case of silicon nitridegraphene composites [24]. In case of spark plasma sintered materials, it was impossible to measure the anisotropy because of too small dimensions of samples and too highsignal damping.

The microstructural observation (Figs. 6, 7) made on SPS obtained composites shows that SPS method did not allow to obtain the graphene orientation in such scale like in the hot-pressed materials. In the case of alumina matrix composite containing 10 mass $\%$ of graphene, there are visible large not oriented agglomerates of graphene. In case of SPSed materials, the white inclusions visible in Figs. 6 and 7 are zirconia phase coming from the milling agent.

The hot-pressed alumina matrix composites were tested in air condition at elevated temperature to determine the maximal working temperature. The mass loss results presented in Fig. 8 show that the materials containing up to 2 mass\% can work up to $1000{ }^{\circ} \mathrm{C}$, because the graphene is still protected from oxygen by alumina matrix. For higher quantities of dispersed graphene phase, the obtained composites can work up to temperature from 550 to $700{ }^{\circ} \mathrm{C}$ dependently on graphene content and the time of work. In case of argon flow, the composites were stable up to $1000{ }^{\circ} \mathrm{C}$.

Table 3 presents data of thermal expansion coefficient that was used to calculate thermal conductivity. The results show that the additions of graphene do not change significantly the value of CTE for the same processing method. Comparing data recorded for sintered bodies obtained by HP method and SPS one, the thermal expansion for composites manufactured by SPS is lower. That can be 


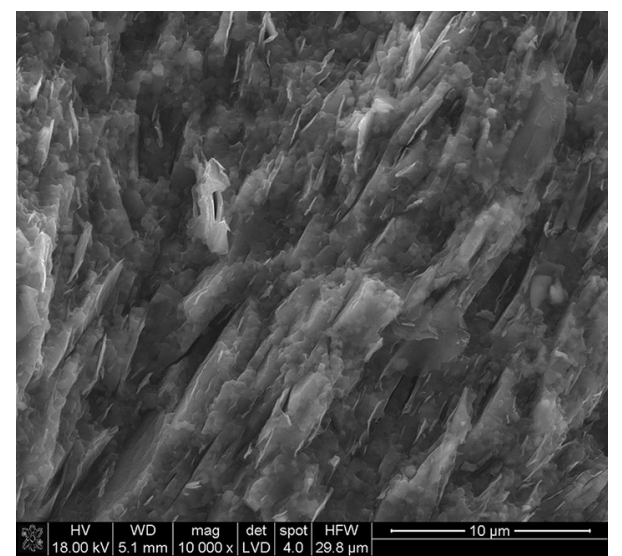

Fig. 4 SEM observations of fracture of hot-pressed composites with 6 mass\% $\mathrm{Gn}(8)$ graphene content

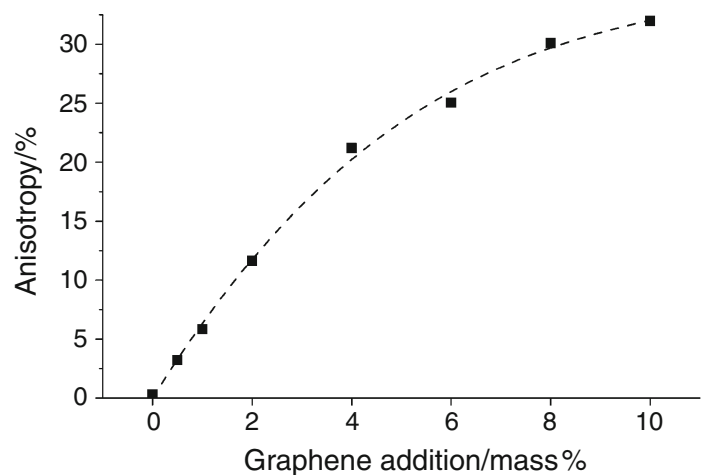

Fig. 5 Anisotropy of hot-pressed alumina-graphene $\mathrm{Gn}(8)$ composites

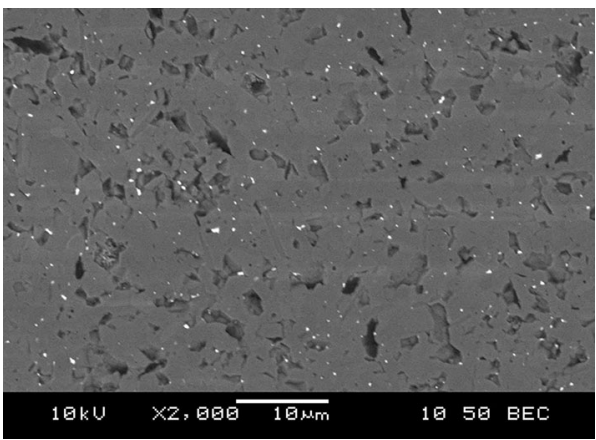

Fig. 6 SEM observations of spark plasma sintered (SPS) alumina composite with 2 mass $\% \mathrm{Gn}(4)$ graphene content

explained by finer grains in the microstructure of SPSed material. The data listed in Table 3 can be used for future computer simulation of manufactured working parts.

The measurement taken by the laser flash analysis (LFA) method allowed directly to determine the thermal diffusivity of tested materials. The earlier ultrasonic experiments and microstructural observations showed the graphene orientation in the manufactured materials. That is

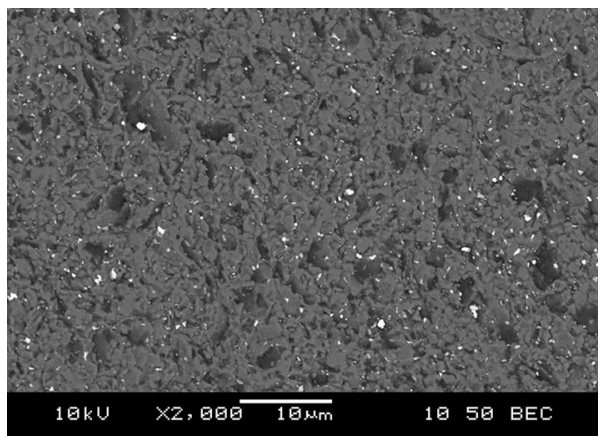

Fig. 7 SEM observations of spark plasma sintered (SPS) alumina composite with 10 mass\% $\mathrm{Gn}(4)$ graphene content

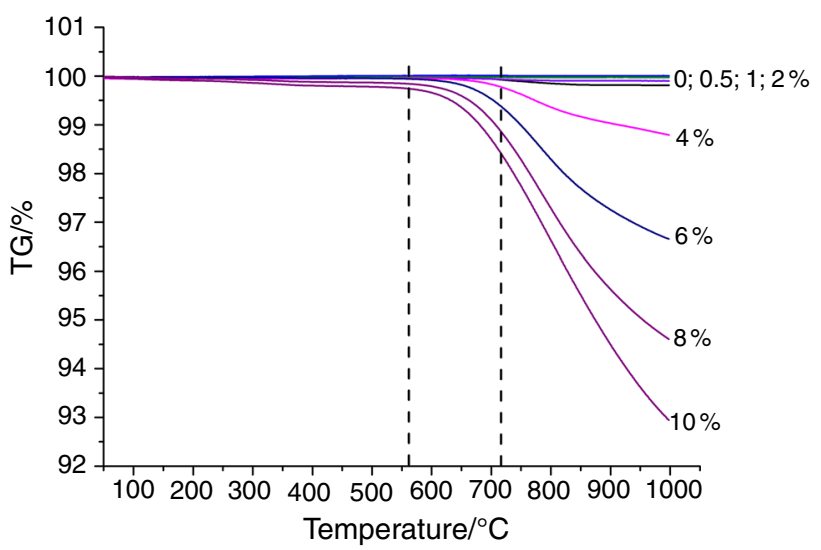

Fig. 8 Thermal stability of hot-pressed alumina-graphene Gn(8) composites

Table 3 Thermal expansion coefficient versus graphene addition and pressing technology

\begin{tabular}{|c|c|c|c|}
\hline \multicolumn{2}{|l|}{ HP } & \multicolumn{2}{|l|}{ SPS } \\
\hline Sample & $\begin{array}{l}\mathrm{CTE} \cdot 10^{-6} / \\
{ }^{\circ} \mathrm{C}^{-1}\end{array}$ & Sample & $\begin{array}{l}\text { CTE } \cdot 10^{-6} / \\
{ }^{\circ} \mathrm{C}^{-1}\end{array}$ \\
\hline 0 mass $\% \mathrm{Gn}(8)$ & 9.5 & 0 mass $\% \mathrm{Gn}(4)$ & 9.2 \\
\hline $\begin{array}{c}0.5 \text { mass } \% \\
\operatorname{Gn}(8)\end{array}$ & 9.6 & $\begin{array}{c}0.5 \text { mass } \% \\
\text { Gn(4) }\end{array}$ & 8.5 \\
\hline 1 mass $\% \mathrm{Gn}(8)$ & 9.4 & 1 mass $\% \mathrm{Gn}(4)$ & 8.7 \\
\hline 2 mass $\% \mathrm{Gn}(8)$ & 9.5 & 2 mass $\% \mathrm{Gn}(4)$ & 8.6 \\
\hline 4 mass $\% \mathrm{Gn}(8)$ & 9.4 & $\begin{array}{c}10 \text { mass } \% \\
\mathrm{Gn}(4)\end{array}$ & 8.2 \\
\hline 6 mass $\% \mathrm{Gn}(8)$ & 9.7 & 2 mass $\% \mathrm{Gn}(8)$ & 8.4 \\
\hline 8 mass $\% \mathrm{Gn}(8)$ & 9.4 & $\begin{array}{r}2 \text { mass } \% \\
\operatorname{Gn}(12)\end{array}$ & 9.2 \\
\hline $\begin{array}{c}10 \text { mass } \% \\
\operatorname{Gn}(8)\end{array}$ & 9.1 & & \\
\hline
\end{tabular}

why the thermal diffusivity was also measured in two different directions: in pressing axis (in direction of applied pressure) and in perpendicular direction to the applied 
Table 4 Thermal diffusivity of alumina-graphene $\mathrm{Gn}(\mathrm{x})$ composites at $25{ }^{\circ} \mathrm{C}$

\begin{tabular}{lllll}
\hline Graphene addition & Pressing method & $\begin{array}{l}\text { Thermal diffusivity in } \\
\text { parallel direction/ } \mathrm{mm}^{2} \mathrm{~s}^{-1}\end{array}$ & $\begin{array}{l}\text { Thermal diffusivity in } \\
\text { perpendicular direction/mm } \mathrm{mm}^{-1}\end{array}$ & $\begin{array}{l}\text { Anisotropy/\% (in comparison } \\
\text { with parallel direction) }\end{array}$ \\
\hline 0 mass\% Gn(8) & HP & $10.628 \pm 0.201$ & $9.733 \pm 0.043$ & $(-) 8.4$ \\
0.5 mass\% Gn(8) & HP & $9.753 \pm 0.106$ & $9.554 \pm 0.041$ & $(-) 2.0$ \\
1 mass\% Gn(8) & HP & $9.206 \pm 0.351$ & $9.765 \pm 0.149$ & $(+) 6.1$ \\
2 mass\% Gn(8) & HP & $7.944 \pm 0.083$ & $9.960 \pm 0.037$ & $(+) 25.4$ \\
4 mass\% Gn(8) & HP & $6.784 \pm 0.095$ & $10.009 \pm 0.078$ & $(+) 47.5$ \\
6 mass\% Gn(8) & HP & $6.450 \pm 0.157$ & $11.363 \pm 0.135$ & $(+) 76.2$ \\
8 mass\% Gn(8) & HP & $5.891 \pm 0.063$ & $9.653 \pm 0.570$ & $(+) 63.9$ \\
10 mass\% Gn(8) & HP & $5.905 \pm 0.074$ & $11.179 \pm 0.428$ & $(+) 89.3$ \\
0 mass\% Gn(4) & SPS & $9.056 \pm 0.034$ & - & - \\
0.5 mass\% Gn(4) & SPS & $8.790 \pm 0.068$ & $5.420 \pm 0.476$ & $(-) 38.3$ \\
1 mass\% Gn(4) & SPS & $8.175 \pm 0.010$ & - & - \\
2 mass\% Gn(4) & SPS & $7.709 \pm 0.016$ & $5.753 \pm 0.611$ & $(-) 25.4$ \\
10 mass\% Gn(4) & SPS & $6.314 \pm 0.065$ & $7.110 \pm 0.139$ & $(+) 12.6$ \\
2 mass\% Gn(8) & SPS & $7.294 \pm 0.045$ & - & - \\
2 mass\% Gn(12) & SPS & $7.186 \pm 0.052$ & - & - \\
\hline
\end{tabular}

Table 5 Specific heat of hot-pressed alumina-graphene Gn(8) composites

\begin{tabular}{lllllllll}
\hline Temp $/{ }^{\circ} \mathrm{C}$ & \multicolumn{3}{l}{ Specific heat $/ \mathrm{J} \mathrm{g}^{-1} \mathrm{~K}^{-1}$} & & & \\
\cline { 2 - 8 } & 0 & 0.5 & 1 & 2 & 4 & 6 & 8 \\
\hline 25 & 0.79 & 0.82 & 0.77 & 0.82 & 0.79 & 0.76 & 0.77 \\
50 & 0.90 & 0.93 & 0.87 & 0.92 & 0.89 & 0.89 & 0.87 & 0.80 \\
100 & 1.03 & 1.02 & 0.98 & 1.02 & 0.99 & 1.01 & 0.99 \\
150 & 1.05 & 1.02 & 1.02 & 1.08 & 1.03 & 1.05 & 1.04 \\
200 & 1.18 & 1.10 & 1.10 & 1.18 & 1.11 & 1.16 & 1.12 \\
500 & 1.52 & 1.28 & 1.30 & 1.37 & 1.39 & 1.52 & 1.10 \\
700 & 1.55 & 1.23 & 1.39 & 1.18 & 1.39 & 1.51 & 1.19 \\
900 & 1.58 & 1.31 & 1.26 & 1.28 & 1.27 & 1.47 & 1.31 \\
\hline
\end{tabular}

Table 6 Specific heat of SPS sintered alumina-graphene composites

\begin{tabular}{|c|c|c|c|c|c|c|c|}
\hline \multirow[t]{2}{*}{$\mathrm{Temp} /{ }^{\circ} \mathrm{C}$} & \multicolumn{7}{|c|}{ Specific heat $/ \mathrm{J} \mathrm{g}^{-1} \mathrm{~K}^{-1}$} \\
\hline & 0 & $0.5 \mathrm{Gn}(4)$ & $1 \mathrm{Gn}(4)$ & $2 \mathrm{Gn}(4)$ & $10 \mathrm{Gn}(4)$ & $2 \mathrm{Gn}(8)$ & $2 \mathrm{Gn}(12)$ \\
\hline 25 & 0.87 & 0.90 & 0.84 & 0.89 & 0.85 & 0.86 & 0.90 \\
\hline 50 & 0.91 & 0.94 & 0.88 & 0.93 & 0.89 & 0.90 & 0.94 \\
\hline 100 & 0.99 & 1.01 & 0.96 & 1.01 & 0.98 & 0.98 & 1.01 \\
\hline 150 & 1.01 & 1.03 & 0.99 & 1.05 & 1.00 & 1.02 & 1.02 \\
\hline 200 & 1.05 & 1.07 & 1.02 & 1.08 & 1.06 & 1.07 & 1.05 \\
\hline 500 & 1.10 & 1.13 & 1.10 & 1.08 & 1.17 & 1.14 & 1.12 \\
\hline 700 & 1.14 & 1.11 & 1.16 & 1.09 & 1.19 & 1.12 & 1.15 \\
\hline 900 & 1.21 & 1.17 & 1.21 & 1.19 & 1.21 & 1.27 & 1.25 \\
\hline
\end{tabular}

pressure. The results listed in Table 4 are for the measurement at room temperature. The calculated anisotropy of thermal diffusivity shows how different thermal diffusivity is in perpendicular direction (in graphene flakes orientation) in comparison with date measured in pressing direction ("minus" indicates decreased values, "plus" indicates increased values). The calculated anisotropy shows that in the case of hot-pressed material, even small 
Table 7 Thermal conductivity and anisotropy of alumina-graphene $\mathrm{Gn}(\mathrm{x})$ composites at $25{ }^{\circ} \mathrm{C}$

\begin{tabular}{lllll}
\hline Graphene addition & Pressing method & $\begin{array}{l}\text { Thermal conductivity in } \\
\text { parallel direction/ } \mathrm{W} \mathrm{m}^{-1} \mathrm{~K}^{-1}\end{array}$ & $\begin{array}{l}\text { Thermal conductivity in } \\
\text { perpendicular direction/ } \mathrm{W} \mathrm{m}^{-1} \mathrm{~K}^{-1}\end{array}$ & $\begin{array}{l}\text { Anisotropy/\% (in comparison } \\
\text { with parallel direction) }\end{array}$ \\
\hline 0 mass\% Gn(8) & HP & $33.6 \pm 0.6$ & $30.6 \pm 0.1$ & $(-) 8.8$ \\
0.5 mass\% Gn(8) & HP & $31.6 \pm 0.3$ & $31.0 \pm 0.1$ & $(-) 2.0$ \\
1 mass\% Gn(8) & HP & $28.1 \pm 1.1$ & $29.6 \pm 0.5$ & $(+) 5.1$ \\
2 mass\% Gn(8) & HP & $24.3 \pm 0.3$ & $31.8 \pm 0.1$ & $(+) 30.6$ \\
4 mass\% Gn(8) & HP & $20.3 \pm 0.3$ & $30.0 \pm 0.2$ & $(+) 47.9$ \\
6 mass\% Gn(8) & HP & $18.0 \pm 0.4$ & $31.9 \pm 0.4$ & $(+) 76.6$ \\
8 mass\% Gn(8) & HP & $16.1 \pm 0.2$ & $26.9 \pm 1.6$ & $(+) 66.9$ \\
10 mass\% Gn(8) & HP & $16.6 \pm 0.2$ & $31.5 \pm 1.2$ & $(+) 89.8$ \\
0 mass\% Gn(4) & SPS & $31.6 \pm 0.1$ & - & - \\
0.5 mass\% Gn(4) & SPS & $31.1 \pm 0.2$ & $19.0 \pm 1.7$ & $(+) 38.9$ \\
1 mass\% Gn(4) & SPS & $27.1 \pm 0.0$ & - & - \\
2 mass\% Gn(4) & SPS & $26.3 \pm 0.1$ & $19.7 \pm 2.1$ & $(-) 25.1$ \\
10 mass\% Gn(4) & SPS & $19.7 \pm 0.2$ & $21.9 \pm 0.4$ & $(+) 11.2$ \\
2 mass\% Gn(8) & SPS & $23.9 \pm 0.2$ & - & - \\
2 mass\% Gn(12) & SPS & $25.5 \pm 0.3$ & - & - \\
\hline
\end{tabular}

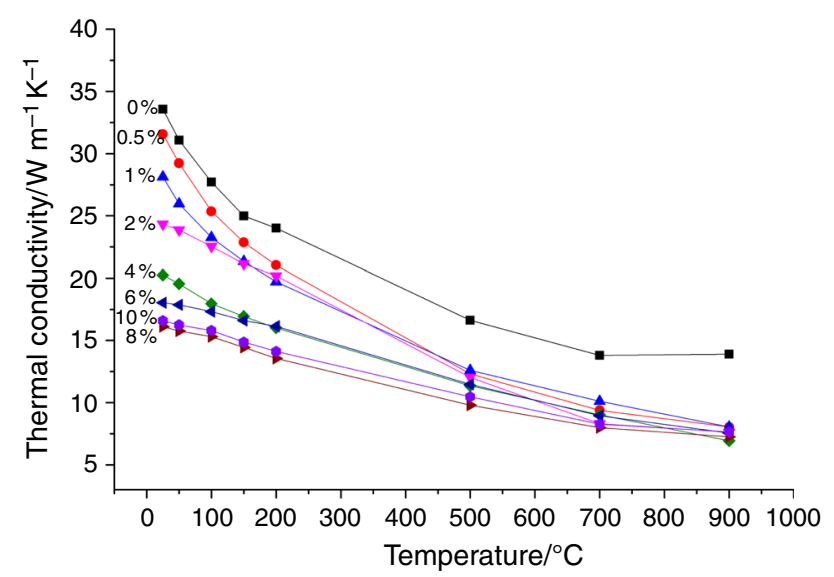

Fig. 9 Thermal conductivity versus temperature of hot-pressed alumina-graphene $\mathrm{Gn}(8)$ composites, in pressing direction

additions of graphene improve thermal diffusivity in perpendicular direction to the applied pressure during the manufacturing process.

Looking at Table 4, the diffusivity in parallel direction to pressing axis of hot-pressed composites decreases with increasing addition of graphene, so in perpendicular direction to the oriented graphene flakes. In the flake direction, the graphene slightly improves thermal diffusivity in comparison with pure alumina. The difference in thermal diffusivity between different directions increases with quantity of introduced graphene. The anisotropy listed in Table 5 reaches even $89 \%$ for addition of 10 mass $\%$ of $\mathrm{Gn}(8)$. Compering different direction for the same graphene content of hot-pressed samples, the addition of graphene improves thermal diffusivity in direction of

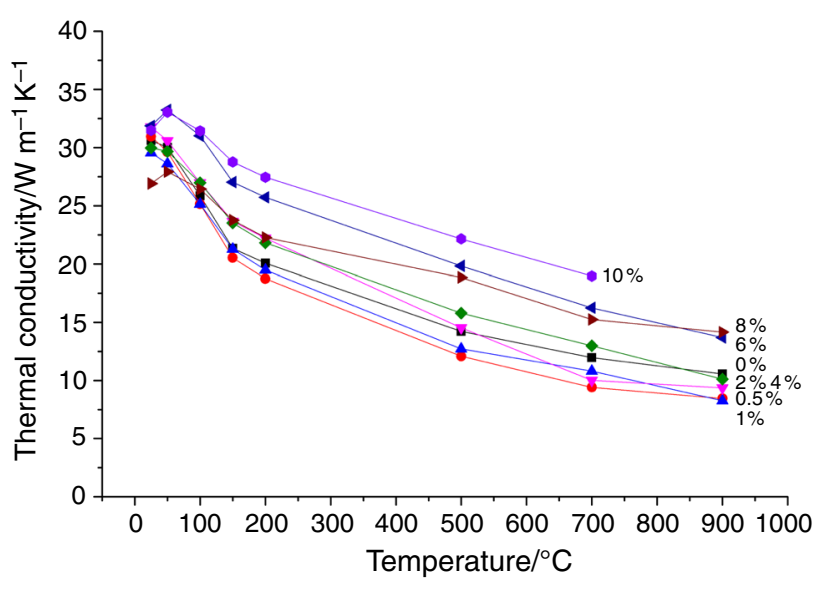

Fig. 10 Thermal conductivity versus temperature of hot-pressed alumina-graphene $\mathrm{Gn}(8)$ composites, perpendicular pressing direction

graphene flakes orientation. In the case of spark plasma sintered composites, the thermal diffusivity is lower than for the same hot-pressed compositions. The difference in density, different graphene particle size and low grain size of matrix can be a plausible reason of lower value of this parameter. Compering measurement directions in case of SPS process, the improvement of thermal diffusivity perpendicularly to pressing direction is visible only for higher concentrations of graphene and probably, it is a result of not oriented agglomerates of graphene Figs. 6 and 7.

To calculate thermal conductivity, the specific heat was calculated on the base of diffusivity data obtained from standard samples, diffusivity of tested material and change of density versus temperature calculated from thermal 


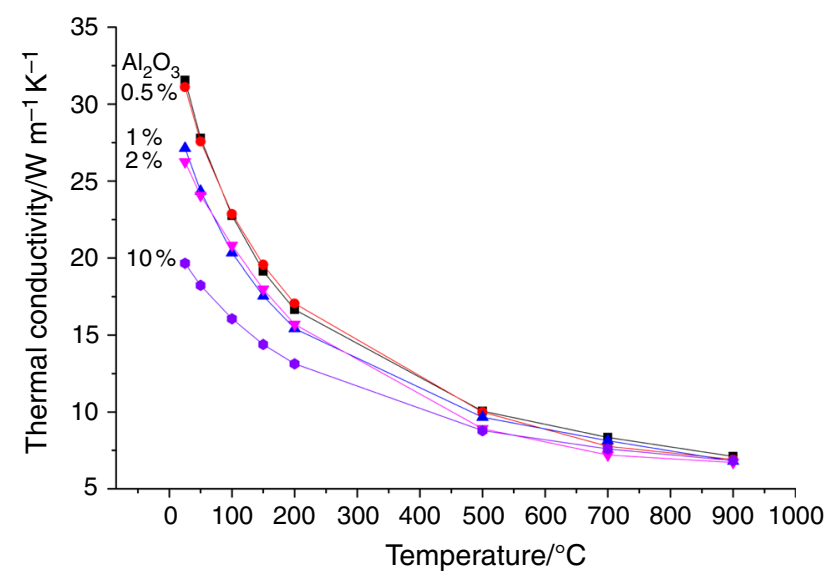

Fig. 11 Thermal conductivity versus temperature of SPS sintered alumina with different addition of graphene $\mathrm{Gn}(4)$ measured in pressing direction

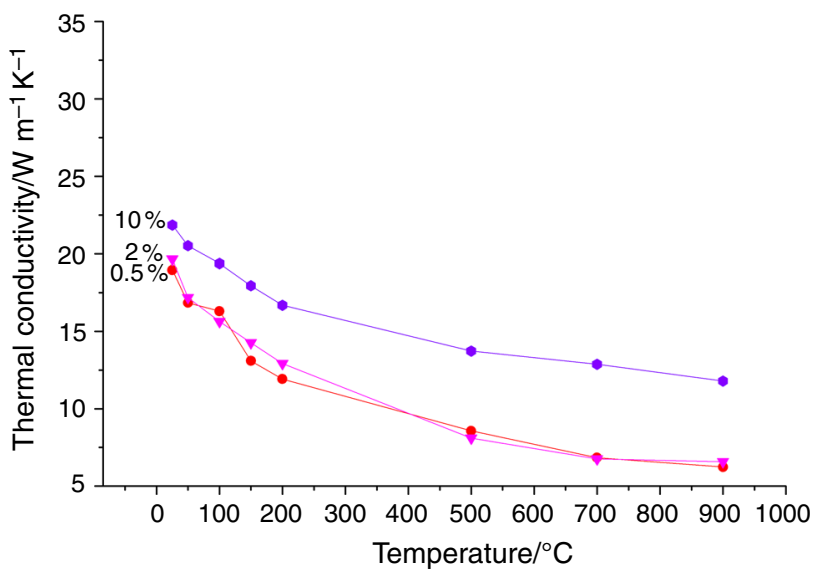

Fig. 12 Thermal conductivity versus temperature of SPS sintered alumina with different addition of graphene $\mathrm{Gn}(4)$ measured in perpendicular direction to pressing axis

expansion coefficient. The data are presented in Table 5 for HP manufactured material and in Table 6 for SPSed composites. The value at room temperature is $0.79-0.82$ $\mathrm{J} \mathrm{g}^{-1} \mathrm{~K}^{-1}$ for hot-pressed materials and little higher $0.84-0.90 \mathrm{~J} \mathrm{~g}^{-1} \mathrm{~K}^{-1}$ for spark plasma sintered ones. At $900{ }^{\circ} \mathrm{C}$, the specific heat is in the range between 1.2 and $1.6 \mathrm{~J} \mathrm{~g}^{-1} \mathrm{~K}^{-1}$.

Thermal conductivity was calculated on the base of thermal diffusivity data, calculated specific heat (Tables 5,6) and the change of apparent density versus temperature. The results at room temperature are presented in Table 7. The apparent/relative density of the sintered bodies plays very important role. For the same sintering temperature (HP process) and increasing graphene content, the density becomes lower, so the calculated thermal conductivity in the direction perpendicular to pressing axis stays almost on the same level as it is for reference material. For direction in pressing axis, so perpendicular to graphene flakes, the thermal conductivity at room temperature decreases dramatically with increasing quantity of graphene. The maximal anisotropy is almost $90 \%$. In case of SPS material, the sample with 10 mass\% Gn(4) shows higher values of thermal conductivity in comparison with HPed material, what can be explained by higher densification of the material. For small additions of graphene, the situation in pressing direction is similar to hot-pressed materials.

The behaviour of thermal conductivity of hot-pressed materials versus graphene addition, measuring temperature and tested direction is presented in Figs. 9 and 10. The graphene addition, in case of measurement taken in pressing axis direction, leads to a decrease of thermal conductivity in temperature function reaching $10 \mathrm{~W} \mathrm{~m}^{-1} \mathrm{~K}^{-1}$ at $900{ }^{\circ} \mathrm{C}$ independently from graphene addition, and the value is much lower than for pure alumina (Fig. 9). The results recorded in perpendicular direction to the applied pressure (during HP process) show the thermal conductivity at $900{ }^{\circ} \mathrm{C}$ depends strongly of graphene content and for $10 \%$ of dispersed phase is even higher than for pure alumina (measured in the same direction) (Fig. 10).

The thermal conductivity results of spark plasma sintered material for $4 \mathrm{~nm}$ graphene are presented in Figs. 11 and 12. In the pressing direction, the situation is similar like for the hot-pressed materials (Fig. 11). In this case, also some inclusions of zirconia, coming from milling agent, can have a negative influence on thermal properties. This impurity can make an increase in intergranular boundaries, which probably results in a decrease in thermal conductivity. Also the value of zirconia thermal conductivity is very low around $2 \mathrm{~W} \mathrm{~m}^{-1} \mathrm{~K}^{-1}$. For the values measured in perpendicular direction to applied pressure (Fig. 12), the increase of thermal conductivity is significant for 10 mass\% of graphene and the value at elevated temperatures is much higher than for pure alumina.

In case of SPSed composite materials, also the influence of type of graphene on thermal conductivity was showed. The results for 2 mass $\%$ of 4,8 and $12 \mathrm{~nm}$ are presented in Fig. 13 and Table 7. The data illustrated in Fig. 13 show that the type of graphene has almost no difference on thermal conductivity at room and elevated temperatures. The shape of the curve is the same. All of used graphene types, in quantity that the materials are thermally stable in air condition (for application purpose), give almost the same decrease in thermal conductivity in comparison with reference alumina. 


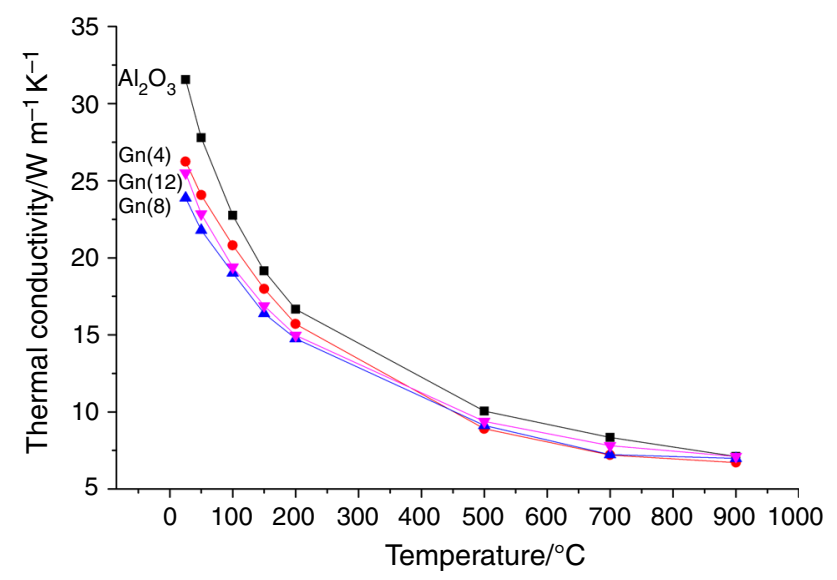

Fig. 13 Thermal conductivity versus temperature of SPS sintered alumina with $2 \%$ addition of different GPL's

\section{Conclusions}

- The hot-pressed alumina-graphene composites show very high microstructural anisotropy, where graphene flakes are perpendicularly directed to the pressing axis. The anisotropy was confirmed by microstructural observations and ultrasonic measurements.

- In the case of HP and SPS techniques, the addition of different amount of various types of graphene leads to a decrease in thermal diffusivity/thermal conductivity measured in pressing direction.

- The increasing content of graphene in hot-pressed alumina matrix composites results in an increase in thermal conductivity in perpendicular direction to pressing axis in comparison with measurement taken in pressing direction for the same graphene content.

- At room temperature, the conductivity in perpendicular direction to pressing axis in case of HP obtained materials does not vary a lot for different content of graphene in comparison with pure polycrystalline alumina.

- In case of SPS obtained composites, the conductivity in perpendicular direction to pressing axis is lower than for pure alumina material and also lower than values measured in pressing direction for the same graphene content (except of 10 mass\%). It is probably caused by lower orientation of graphene flake in comparison with hot-pressed materials.

- The thermogravimetric measurement taken on hotpressed composites shows that materials with up to 2 mass\% of graphene can be used as working parts in air at high temperatures. Higher additions of graphene decrease the working temperature $550{ }^{\circ} \mathrm{C}$. For argon flow, all composites were stable at the temperature of $1000{ }^{\circ} \mathrm{C}$.
- The thermal conductivity measurement of spark plasma sintered composites shows that the kind of graphene has no significant influence on thermal conductivity at low its content.

Acknowledgements The study constitutes a part of the Project No. GRAF-TECH/NCBR/03/05/2012 "Ceramic-graphene composites for cutting tools and devices parts with unique properties". Thank to Dr. Wojciech Piekarczyk for help with ultrasonic measurements.

Open Access This article is distributed under the terms of the Creative Commons Attribution 4.0 International License (http:// creativecommons.org/licenses/by/4.0/), which permits unrestricted use, distribution, and reproduction in any medium, provided you give appropriate credit to the original author(s) and the source, provide a link to the Creative Commons license, and indicate if changes were made.

\section{References}

1. Hvizdoš P, Dusza J, Balázsi C. Tribological properties of $\mathrm{Si}_{3} \mathrm{~N}_{4-}$ graphene nanocomposites. J Eur Ceram Soc. 2013;33:2359-63.

2. Kvetkova L, Duszowa A, Kasiarova M, Dorcakova F, Dusza J, Balázsi C. Influence of processing on fracture toughness of $\mathrm{Si}_{3} \mathrm{~N}_{4}+-$ graphene platelet composites. J Eur Ceram Soc. 2013;33:2299-304.

3. Pfeifer J, Sáfrán G, Wéber F, Zsigmond V, Koszor O, Arató P, Balázsi C. Tribology study of silicon nitride-based nanocomposites with carbon additions. Mater Sci Forum. 2010;659:235-8.

4. Walker LS, Marotto VR, Rafiee MA, Koratkar N, Corral EL. Toughening in graphene ceramic composites. ACS Nano. 2011; 5:3182-90.

5. Ramireza C, Miranzoa P, Belmontea M, Osendia MI, Pozab P, Vega-Diazc SM, Terronesc M. Extraordinary toughening enhancement and flexural strength in $\mathrm{Si}_{3} \mathrm{~N}_{4}$ composites using graphene sheets. J Eur Ceram Soc. 2014;34:161-9.

6. Dusza J, Morgiel J, Duszová A, Kvetková L, Nosko M, Kun P, Balázsi C. Microstructure and fracture toughness of $\mathrm{Si}_{3} \mathrm{~N}_{4}+-$ graphene platelet Composites. J Eur Ceram Soc. 2012;32:3389-97.

7. Kvetkova L, Duszová A, Hvizdoš P, Dusza J, Kun P, Balázsi C. Fracture toughness and toughening mechanisms in graphene platelet reinforced $\mathrm{Si}_{3} \mathrm{~N}_{4}$ composites. Scr Mater. 2012;66:793-6.

8. Rahman A, Singh A, Karumuri S, Harimkar SP, Kalkan KA, Singh RP. Graphene reinforced silicon carbide nanocomposites: processing and properties. Composite, hybrid, and multifunctional materials. In: Conference proceedings of the society for experimental mechanics series. 2015;4:165-176.

9. Rutkowski P, Stobierski L, Zientara D, Jaworska L, Klimczyk P, Urbanik M. The influence of the graphene additive on mechanical properties and wear of hot-pressed $\mathrm{Si}_{3} \mathrm{~N}_{4}$ matrix composites. J Eur Ceram Soc. 2015;35:87-94.

10. Porwal H, Tatarko P, Grasso S, Khaliq J, Dlouhý I, Reece MJ. Graphene reinforced alumina nano-composites. Carbon. 2013;64:359-69.

11. Liu J, Yan H, Jiang K. Mechanical properties of graphene platelet-reinforced alumina ceramic composites. Ceram Int. 2013;39: 6215-21.

12. Wang K, Wang Y, Fan Z, Yan J, Wei T. Preparation of graphene nanosheet/alumina composites by spark plasma sintering. Mat Res Bull. 2011;46:315-8.

13. He T, Li J, Wang W, Zhu J, Jiang W. Preparation and consolidation of alumina/graphene composite powders. Mater T. 2009; 50:749-51. 
14. Porwal H, Grasso S, Reece MJ. Review of graphene-ceramic matrix composites. Adv Appl Ceram. 2013;112:443-54.

15. Berdova M, Perros AP, Kim W, Riikonen J, Ylitalo T, Heino J, Li C, Kassamakov I, Hæggström E, Lipsanen H, Franssila S. Exceptionally strong and robust millimeter-scale graphene-alumina composite membranes. Nanotechnology. 2014;25:355701.

16. Liu X, Fan Y-C, Li J-L, Wang L-J, Jiang W. Preparation and mechanical properties of graphene nanosheet reinforced alumina composites. Adv Eng Mater. 2014. doi:10.1002/adem.201400231.

17. Jiwei T, Yunqi L, Shuang T, Dandan L, Chenguang L. Fabrication of alumina/graphene composite and its catalytic application property in the selective hydrodesulfurization of fcc gasoline oil, www.paper.edu.cn

18. Nieto A, Lahiri D, Agarwal A. Synthesis and properties of bulk graphene nanoplatelets consolidated by spark plasma sintering. Carbon. 2012;50:4068-77. doi:10.1016/j.carbon.2012.04.054.

19. Jastrzębska AM, Olszyna AR, Jureczko J, Kunicki A. New reduced graphene oxide/alumina $\left(\mathrm{RGO} / \mathrm{Al}_{2} \mathrm{O}_{3}\right)$ nanocomposite: innovative method of synthesis and characterization. Appl Ceram Technol. 2013. doi:10.1111/ijac.12183.
20. Liu X, Fan Y, Feng Q, Wang L, Jiang W. Preparation of graphene nanosheet/alumina composites. Mater Sci Forum. 2013;745746:534-8.

21. Wonbong C, Lee J-W. Graphene, synthesis and applications. Boca Raton: CRC Press; 2012.

22. Warner JH, Schaffel F, Bachmatiuk A, Rummeli MH. Graphene, fundamentals and emergent applications. North Holland, NY: ELSEVIER; 2013.

23. Rutkowski P, Piekarczyk W, Stobierski L, Górny G. Anisotropy of elastic properties and thermal conductivity of $\mathrm{Al}_{2} \mathrm{O}_{3} / \mathrm{h}-\mathrm{BN}$ composites. J Therm Anal Calorim. 2013;115:461-6.

24. Rutkowski P, Stobierski L, Górny G. Thermal stability and conductivity of hot-pressed $\mathrm{Si}_{3} \mathrm{~N}_{4}$-graphene composites. J Therm Anal Calorim. 2014;116:321-8. 